\title{
Evidential Value of Microobjects in Criminal Proceedings and Forensic Rules for Handling Them
}

\author{
Svoboda Eugenia \\ PhD of Juridical Sciences, Associate Professor, Professor of Department of \\ Forensic Support and Forensic Expertise of the National Academy of Internal \\ Affairs, Kiev, Ukraine \\ ORCID ID 0000-0002-8639-8333_jeechka@ukr.net
}

\section{Pavlovska Nataliia}

PhD of Juridical Sciences, Associate Professor, Professor of Department of Civil Law and Process of the National Academy of Internal Affairs, Kiev, Ukraine ORCID ID 0000-0003-3311-0364 wwwpav@gmail.com

\section{Herasymenko Larysa}

PhD of Juridical Sciences, Associate Professor, Head of Department of Economic Security and Financial Investigations of the National Academy of Internal Affairs, Kiev, Ukraine

ORCID ID 0000-0001-6340-1061lora-gera@ukr.net

\section{Morhun Nadiia}

PhD of Juridical Sciences, Professor of Department of Economic Security and Financial Investigations of the National Academy of Internal Affairs, Kyiv, Ukraine

ORCID ID 0000-0002-2997-9975 Morgun.nadiy@gmail.com

\section{Kutsyi Roman}

PhD of Juridical Sciences, Senior Teacher of Criminal Law Disciplines and Operative and Investigative Activities of the Precarpathian Department of the National Academy of Internal Affairs, Kyiv, Ukraine ORCID ID 0000-0002-1979-7019 romakrv2009@ukr.net

\footnotetext{
Abstract

The use of micro-objects in the process of investigating crimes has been considered for many decades an independent area of forensic expertise. Among physical evidence subject to microscopic examination, a special place has always been occupied by various material small bodies (objects) in the form of dust and soil
} 
compounds, various fibres (hairs) of human, animal and plant origin, paint and sawdust particles, stains, various types of contamination, pollen and plant particles as well as substances of various origin, which are as a rule associated with the crime.

Key words: the concept and classification of micro-objects;value, detection, fixation, removal, packaging, possibilities of forensic examination of microobjects.

Introduction The study of micro-objects for the purposes of criminal proceedings has been widely reflected in the works of domestic forensic scientists: V. H. Honcharenko, H. L. Hranovskyi, N. I. Klymenko, O. A. Kyrychenko, N.O. Prokopenko, O. V. Nenia and many others.

Micro-objects are classified into many types; they have multi-dimensional links with events under investigation and contain significant investigative and probative information. Micro-objects can be barely visible or invisible; thus, they are difficult to destroy while hiding traces of a crime. This is especially important as modern criminals are "well-educated" and it is widely known how to identify persons by fingerprints, weapons, by traces on bullets and bullet casings or to identify the author of a hand-written text by his or her handwriting, and achievements in forensic face recognition and other traditional types of forensic examination are well-known.

\section{The forensic examination of micro-objects and its opportunities.}

First of all, micro-objects can be preliminarily examined directly on the scene. Such examination is not regulated by law, and it is a non-procedural way of dealing with material items. An important requirement concerning the preliminary examination of micro-objects is that they should be stored in the same form in which they were removed. Micro-objects may be destroyed or wasted only if there are large quantities of homogeneous objects. If microobjects are removed, transferred or extracted, this can completely devalue the fact of their detection as evidence.

Preliminary examination of micro-objects is done to meet the following objectives:

their detection on the carrier;

tentative identification of their nature (to search for comparative samples);

finding out how they were formed;

comparison with the material of specific items (to decide whether it is feasible to submit them for further examination) [1]. 
Preliminary examination of micro-objects facilitates making decisions to open criminal proceedings; suggesting versions in the case; developing investigative measures and tactics of specific actions; ordering forensic examination and formulating relevant questions.

An example. There are no rope fibres on the victim's arms. The suicide version is called into question. This was usually followed by references to a comment to Articles 115 of the $\mathrm{CrCU}[2]$.

To conduct an expert examination, it is necessary to prepare the relevant materials properly:

provide control and comparative samples (preferably the entire source);

provide additional initial data (aspects of their use, origin, conditions under which they were extracted, information on whether any changes occurred during the identification period);

the relevant order should indicate what items were removed, the place, time and circumstances of their removal, contacts, actions before and after removal, conditions under which they were used and stored following the crime;

the order should also adequately define the objectives, areas and scope of the examination.

It is important to correctly determine the type of expert examination of micro-objects and the main expert institution [3].

Preliminary research of micro-objects is still best done in a laboratory, because, as a rule, lab-based stationary facilities and method are necessary to obtain information that is important for the detection of a crime [17].

Qualified professionals with relevant expertise are needed to conduct preliminary examinations. Therefore, an investigator who knows typical traces which different crimes leave and the ways they are being left is obliged to select a professional with necessary qualifications to handle micro-objects, as the results of preliminary examinations conducted by a forensic expert are not always of significant help in the detection and investigation of a crime [4].

It should be kept in mind that micro-objects may render identification possible if it is established that the object of identification is the source of them or if it is concluded that there 
has been a contact interaction. Indirect identification of the perpetrator or the victim is carried out by establishing the link between the objects of identification and these persons [16].

With the help of micro-objects, it is possible to identify perpetrators if such objects are found on the body and personal belongings of the suspect and are characteristic of the scene or are inherent to the clothes and body of the victim, his or her belongings found on the scene; on weapons or other items which were left on the scene and are typical of the suspect or his belongings; or if homogeneous extraneous microparticles are found on both the suspect and the victim [5].

The examination of the properties of micro-objects also helps to identify signs pointing to the perpetrator and the victim, their appearance, sex, clothing (micro-objects of hair, nails, secretions, powder, lipstick, fibres, nail polish fragments, etc.) [14].

For example, in November 2008, criminals who robbed a farm and killed its guard in the Mykolaiv region made almost every possible effort to destroy traces left by them by getting rid of gloves and footwear in which they committed the crime. However, such a little detail as the fibres from the gloves left on the instruments, albeit thrown away later, of the crime made it possible to quickly identify the witness (the seller in the store where the criminals bought their gloves). The officers together with the expert made facial composites of criminals, which made it possible to determine correct investigative avenues, identify criminals and solve the crime later on (O. V. Nenya, 2011). This was usually followed by references to a comment to Articles 115 and 186, 187 of the $\mathrm{CrCU}$ [2].

It is possible to identify the blood type of a person by the layering of the sweat and grease deposit substance of his/her fingerprint and compare it with the data of forensic examination of the suspect's blood.

Micro-objects can be used to identify the place of a crime [15].

The place of the crime can be identified by the particles of soil or paint, which have been stuck to the clothes (body) of the victim or suspect, other contaminants originating from a certain area, microparticles of items belonging to the scene or broken obstacles [6].

Particles found on the scene and detached from clothing, footwear, vehicles (fragments of paint and headlights, drops of fuel and lubricants, dirt), indicate that such items have been present in a particular place. Therefore, the detection of microparticles on the items on the scene makes it possible to determine how the offender got there, the routes of his/her 
movements, whether specific items have been moved, etc. The following example is quite interesting as it involves professionals of the expert unit of the Ministry of Internal Affairs of Ukraine (hereinafter, MIA) who preliminarily investigated the found particles which made it possible to narrow as much as possible the search for the crime site and quickly identify the victim and his residence. In September 2008, human body fragments were found in the Lviv region. Examination of the scene around one of the body fragments revealed stains of brown substance (the research found them to be human blood), mostly oval in shape. It was assumed judging from the form of the stains that they possibly fell down from an object that moved from one of the residential buildings where stains ended. Therefore the officers inspected this building and the adjacent ones and interviewed their residents. On the walls of that building, between the second and third floors, dark smears were found, resembling human blood, and the residents of this building recognized the victim as their neighbour. The flat of the victim was inspected, and another human body fragment was found, a number of items were retrieved to be examined, among them 22 stretches of sticky transparent tape with handprints. Following the research and checks on the basis of the retrieved handprints, two suspects were apprehended who, after being presented with the evidence, confessed to this crime and named their five accomplices (Nenia O. V., 2011). This was usually followed by references to a comment to Articles 115 of the CrCU [2].

The absence of micro-objects where, as the situation suggests, they should have been detected, or the presence of micro-objects with other (unexpected) properties can be regarded as a negative circumstance and provide the ground for suspecting faking, false testimony, deliberate changes of the crime scene. Identification of various objects involved in the crime by their micro-objects is important for the investigation process. It is possible to identify them either when an expert confirms that the item (the group of items) to be identified was the source of such micro-objects or if there is a conclusion that the items had a contact interaction between them. People are indirectly identified by establishing links between these items and the offender or victim [7].

Items are often identified when micro-objects are examined on weapons or the tools that caused injuries. 
In the practice of investigating traffic accidents, it is common to identify repaired or painted vehicles by multi-layer microparticles of paint [18]. This was usually followed by references to a comment to Articles 286 of the $\mathrm{CrCU}$ [2].

Micro-objects are important for establishing the fact of contact interaction, especially in the investigation of crimes such as rape, murder or grievous bodily harm. Such facts are established based on micro-objects which translocated from the clothes (bodies) of the suspect and victim. These may be tissue fibres, drops of blood, sperm, saliva, sweat, other secretions, extraneous contaminants originating from the victim and the assailant; particles from the weapon used which remained on the clothes of the offender and on the body and clothes of his/her victim [8]. This was usually followed by references to a comment to Articles 152, 115 and 121 of the $\mathrm{CrCU}$ [2].

Micro-layers of sooting between the little and the ring finger and between thumb and forefinger (detected by examination in infrared rays) confirm that shots have been made from handguns. If a revolver was used, stippling can be revealed, in addition to sooting. The use of long guns can be proved by micro-layers of sooting on the hands, face and clothing of the shooter; besides, they provide information about the type of the weapon used [13].

Microparticles found on the crime weapon make it possible to establish the fact of its use in the crime under investigation. For example, if the blade of a puukko knife contains microfibres from various items of clothing of the victim, blood stains (particles) and epithelial cells of the injured organs, this suggests that the weapon was actively used in this crime.

In March 2009, textile fibres were found on the clothes of two victims of stab wounds in Zaporizhzhia, one of whom died; the general type of these fibres coincided with the type of textile fibres that were part of the fabric of the sweater seized from the suspect. The suspect, after being informed of the expert research results, pleaded guilty (Nenia, O. V., 2011). This was usually followed by references to a comment to Articles 121 of the $\mathrm{CrCU}$ [2].

It is possible to identify, on the basis of micro-objects, the vehicle which has caused injuries. Microfibres of the victim's outerwear, stains of his/her blood, etc., often remain on those parts of the car, which contacted with the victim [18]. This was usually followed by references to a comment to Articles 286 of the $\mathrm{CrCU}$ [2].

Micro-objects can inform the investigator of the skills and professional abilities of persons involved in the crime. Various particles (tobacco, metals, wood (sawdust, shavings), 
micro-pollution by various substances and materials (paint, lubricants and building materials, etc.) and micro-objects of the soil of plant and animal origin can indicate occupation or profession [9].

Micro-objects play an important role in establishing the time of the crime. Time can be determined by examining microparticles of biological origin: microorganisms that have developed, in particular, on the corpse; pollen, seeds of plants, algae, etc., found on it [10].

Sometimes it is possible to find the perpetrator by the "microparticles of smell", i.e. the molecules of complex compounds contained in any excretions of a human body or such that can be exhaled with the air. Specially trained dogs are used as analysers for that. An example of this can be the incident that occurred in February 2008 in the Vinnytsia region, where an unknown person broke into the premises of a gas station and wounded the cashier with a firearm. A pistol was found on the scene and traces of odours on the handle of the weapon. The police also found a pistol magazine with three bullets and traces of odours from the seats of a car found not far from the scene. A suspect was apprehended following the investigation. The experts who conducted forensic odorology proved the complete coincidence of the odour traces extracted from the pistol grip and the car seat with the sample taken from the detainee. The forensic firearm examination revealed that the cartridge case found during the inspection of the scene was fired from the pistol left on the scene. The suspect, after being informed of the results of forensic examinations, pleaded guilty (Nenia, O. V., 2011). This was usually followed by references to a comment to Articles 187 and 263 of the $\mathrm{CrCU}$ [2].

Micro-objects may facilitate proposing and verifying investigation avenues. For example, microfibres left by the offender on the scene or while moving, help to get an idea about his/her outerwear. This can narrow the number of potential suspects and facilitate the investigation [11].

Micro-objects are also widely used to determine the causes of fires and explosions and to investigate aircraft crashes. This was usually followed by references to a comment to Articles 194, 263 and 276, 416 of the $\mathrm{CrCU}$ [2] .

It should also be noted that the significance of micro-objects as evidence can be compromised or even totally lost if rules regulating their search, fixation, extraction, storage and examination are violated. Physical evidence can be substituted, micro-objects formed at 
the time of the crime can be lost, and other micro-objects can appear with no connection to the event under investigation [12].

Conclusions To sum up, micro-objects can be extremely widely used. As a rule, micro-objects can be found during the investigative inspection of the crime scene, the corpse and the places where physical evidence are most likely to be found, with due regard to the specific circumstances and modalities of a crime.

Micro-objects are material formations which under certain circumstances can be physical evidence used in proceedings; therefore, they should be detected and fixed following the established procedures. In particular, all the circumstances related to the detection of micro-objects, their characteristics, fixation methods, whether and in what way they were added to the record, should be reflected in the record of the investigation in compliance with Articles of the Criminal Procedural Code [19].

If micro-objects are intended to become physical evidence then the inquirer, investigator, prosecutor or the court should issue an order that all found micro-objects and the items which are assumed to be the carriers of micro-traces, should be added to the case file [20].

Therefore, from the point of view of the criminal process, micro-objects can be used as material evidence only if detected, described and extracted during the investigative inspection, and in case of their latency as traces on the carrier (a piece of material evidence), their detection, description and extraction should be carried out by an expert entrusted with the relevant examination. At the same time, a mandatory condition for the recognition of microobjects as the physical evidence is that the investigator should add them to the case file following the procedural order. Moreover, the preliminary recognition of micro-objects as material evidence includes, as a necessary stage, the procedure of their examination to establish their linkage with the crime. As micro-objects are carriers of evidential information, such their status determine a specific range of objectives to be achieved during their expert examination.

To sum up, one of the most promising avenues to enhance the efficiency of law enforcement is the extensive use of micro-objects, which, regardless of the offender's intentions, almost always remain on the scene and contain important forensic information 
which can be obtained during their preliminary investigation on the scene and following their comprehensive expert research.

\section{References}

1. Instruction on the procedure for involving employees of pre-trial investigation bodies of the police and the Expert Service of the Ministry of Internal Affairs of Ukraine as specialists to participate in the inspection of the scene, approved by the order of the Ministry of Internal Affairs of Ukraine of 3 November 2015 № 1339. URL: http://zakon3.rada.gov.ua/laws/show/z1392-15

2. Criminal Code of Ukraine. URL: https://zakon.rada.gov.ua/laws/show/2341-14\#Text

3. Nenia, O. V., The forensic importance of micro-objects in the investigation of crimes, Visnyk Akademii advokatury Ukrainy, 2011, No. 2(21), pp. 139-145.

4. Prokopenko, N. O., Theoretical principles and practice of research of microscopic traces and reflections, abstract of the thesis, Kyiv, 2009.

5. Forensic support of crime-solving and investigation: practice, experience, problems, Krasiuk, I. P. (ed.), Kyiv, DNDEKTS MIA of Ukraine, 2009, No. 14.

6. Forensic support of crime-solving and investigation: practice, experience, problems, Krasiuk, I. P. (ed.), Kyiv, DNDEKTS MIA of Ukraine, 2009, No. 15-16

7. Honcharenko, V. H., Issues related to the use of micro-objects in proving, Advokat, 2008, No. 4(91).

8. Forensic support of crime-solving and investigation: practice, experience, problems, Krasiuk, I. P. (ed.), Kyiv, DNDEKTS MIA of Ukraine, 2008, No. 13

9. Klymenko, N. I. The use of micro-objects to investigate crimes: methodological textbook, Klymenko N. I., Liniuchev H. V., Krasiuk, I. P. (ed.), Kyiv, DNDEKTS MIA of Ukraine, 2008.

10. Davydova, O. O. Forensic examination of materials, substances and products, Lecture series, Kyiv, KNT, 2008.

11. Zinin, A. M., Forensics, a textbook, Zinin, A. M., Mailis, N.P., Moscow, 2002.

12. Vander, M.B., The use of microparticles to investigate crimes, St. Petersburg, Piter, 2001

13. Ishchenko, P. P. Micro-objects in the investigative and expert practices, Volgograd, the High Investigative School of the MIA of the USSR, 1987.

14. Klymenko, N. I. The use of micro-objects to investigate crimes: methodological guidance for the law students, Kyiv, KGU, 1984.

15. Klymenko, N. I. Micro-objects as physical evidence: methodological guidance for investigators, Klymenko, N. I., Bovsunovskyi, V. M., Kyiv, Editorial department of the MIA of the Ukrainian Soviet Socialist Republic, 1984.

16. The participation of a forensic expert in some investigative actions. URL: http://elar.naiau.kiev.ua/jspui/handle/123456789/16325 
17. Forensics: lecture notes, Kobylianskyi, O. L., Kofanov, A. V., Kyiv, 2019.

18. Forensic studies of paint and varnish materials. URL: http://elar.naiau.kiev.ua/jspui/handle/123456789/2991

19. General principles of forensic research of materials, substances and products. URL: http://elar.naiau.kiev.ua/jspui/handle/123456789/2997

20. Practical aspects of forensic research of materials, substances and products. URL: http://elar.naiau.kiev.ua/jspui/handle/123456789/2996 